\title{
Elevated body swing test after focal cerebral ischemia in rodents: methodological considerations
}

\author{
Edvin Ingberg ${ }^{1 *}$, Johanna Gudjonsdottir ${ }^{1}$, Elvar Theodorsson ${ }^{1}$, Annette Theodorsson ${ }^{1,2}$ and Jakob O Ström ${ }^{1,3,4}$
}

\begin{abstract}
Background: The elevated body swing test (EBST) is a behavioral test used to evaluate experimental stroke in rodents. The basic idea is that when the animal is suspended vertically by the tail, it will swing its head laterally to the left or right depending on lesion side. In a previous study from our lab using the EBST after middle cerebral artery occlusion (MCAo), rats swung contralateral to the infarct day 1 post-MCAo, but ipsilateral day 3 post-MCAo. This shift was unexpected and prompted us to perform the present study. First, the literature was systematically reviewed to elucidate whether a similar shift had been noticed before, and if consensus existed regarding swing direction. Secondly, an experiment was conducted to systematically investigate the suggested behavior. Eighty-three adult male and female Sprague-Dawley rats were subjected to MCAo or sham surgery and the EBST was performed up to 7 days after the lesion.

Results: Both experimentally and through systematic literature review, the present study shows that the direction of biased swing activity in the EBST for rodents after cerebral ischemia can differ and even shift over time in some situations. The EBST curve for females was significantly different from that of males after the same occlusion time $(p=0.023)$.
\end{abstract}

Conclusions: This study highlights the importance of adequate reporting of behavioral tests for lateralization and it is concluded that the EBST cannot be recommended as a test for motor asymmetry after MCAo in rats.

Keywords: Brain infarction, Focal cerebral ischemia, Middle cerebral artery occlusion, Elevated body swing test, Rodents, Rats, Lateralization

\section{Background}

Stroke is one of the most devastating diseases in terms of mortality and disability [1]. In addition to the effects on patients and relatives, it imposes a substantial economic burden on the society [1]. Despite major research efforts providing improved understanding of stroke mechanisms the available treatment options are still few [2]. Preclinical stroke studies are mainly performed in rodents subjected to ischemic stroke, most commonly by middle

\footnotetext{
${ }^{*}$ Correspondence: edvin.ingberg@liu.se

${ }^{1}$ Division of Microbiology and Molecular Medicine, Department

of Clinical and Experimental Medicine, Department of Clinical Chemistry,

Faculty of Health Sciences, Center for Diagnostics, Linköping University,

Region Östergötland, Linköping, Sweden

Full list of author information is available at the end of the article
}

cerebral artery occlusion (MCAo). The outcome measure, for example to evaluate the effect of a drug, has traditionally been infarct size but it is nowadays common to also include behavioral testing as an endpoint. Numerous such tests have been developed with the intention of examining how the stroke-induced animal is affected regarding sensory, motor or cognitive function or the emotional status [3].

Among the tests used for evaluation of motor functions is the elevated body swing test (EBST). Although a similar procedure was described as early as 1979 [4], the test in its current form was developed 1995 by Borlongan and Sanberg as a test for asymmetrical motor behavior in an animal model of Parkinson's disease [5]. Soon after this, the EBST was employed by the same research group 
also in animal studies of Huntington's disease [6] and ischemic stroke [7]. The basic idea is that when the animal is lifted by the tail and held vertically, it will swing its head to the left or to the right. Whereas healthy animals on a group level are likely to swing approximately $50 \%$ to either side, animals with a unilateral cerebral lesion, e.g. ischemic stroke, should present with a dominant/biased swing direction. The extent of such biased swing activity, for example overweight of swings to the rats' right side, is suggested to be a measure of lateralization of motor behavior. The first stroke study using EBST described swings favoring the side ipsilateral to the lesion, and the test has subsequently been used to evaluate lesions in a number of preclinical ischemic stroke studies with rats [7-32], mice [33-35] and gerbils [36-38], as well as to confirm successful surgery for inclusion [39] (results from all these studies are presented herein). The two widely used neurological scoring exams for MCAo studies designed by Bederson [40] and Garcia [41], are also somewhat related to the EBST; both of these include a step where the rat is held by the tail and symmetry of motor behavior is assessed.

In a previous study from our lab [42], one of the outcomes was the EBST (performed 1 and 3 days after MCAo), and an interesting phenomenon was observed. During testing day 1 post-MCAo, the rats in two out of three stroke groups swung predominantly to the side contralateral to the ischemic hemisphere (from here on, contralateral or ipsilateral refer to direction of swings in relation to the ischemic hemisphere), but had day 3 postMCAo developed an ipsilateral side bias (Fig. 1). This shift was highly unexpected, and encouraged us to further investigate the phenomenon. Hence, we performed

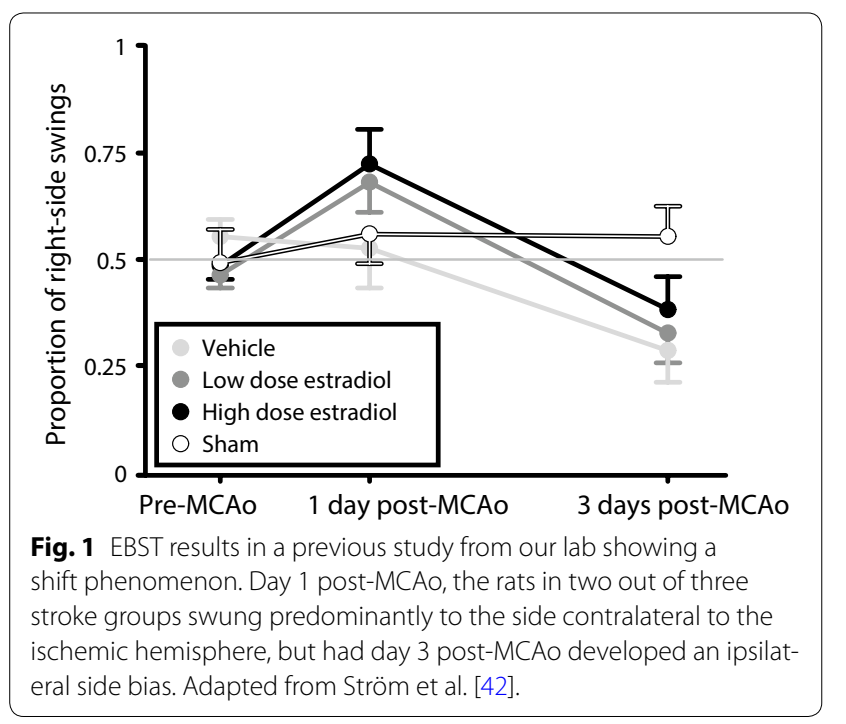

the current study consisting of two steps: first, the literature was systematically searched for studies using the EBST after ischemic stroke in rodents to elucidate if the shift that we observed had been noticed before, and if consensus existed regarding swing direction. Secondly, an experiment was conducted to systematically investigate the suggested shifting behavior in the EBST and further how robust the phenomenon was to alterations in methodology, both regarding sex of the animals and infarct size (occlusion time).

\section{Methods}

\section{Systematic review}

In addition to our abovementioned study (Fig. 1; [42]), the Medline database was searched through PubMed for papers with the EBST using the search string (stroke or "cerebral ischemia") and ("elevated body swing" or EBST or "tail suspension"). Papers published up until June 2014 were reviewed $(n=36)$. An article was included if the following criteria were met:

1. Article written in English.

2. Rodents were subjected to unilateral cerebral ischemia.

3. At some point after the induced ischemia, the animals were suspended by their tails and the directions of the head and body movements were recorded.

Subsequently, in the included papers retrieved by the Medline search $(\mathrm{n}=22)$, the descriptions of the EBST in the methods sections were searched for references. If criteria were met in these referred articles, they were also included $(\mathrm{n}=10)$. From all the included papers ( $\mathrm{n}=33$; Fig. 2), information regarding whether the stroked animals in the studies swung mainly towards the side contralateral or ipsilateral to the ischemic hemisphere, or if there was no biased swing activity, was extracted. If no statistical comparison had been performed, an explicit statement that the swing activity was biased towards the contralateral or the ipsilateral side was accepted. In cases where no information was provided regarding direction of the biased swing activity, the swing direction was labeled as "unclear". One group showing biased swing activity was considered enough to label the paper as either contralateral, ipsilateral, unclear or with a shift over time, even though other groups in the same study might have presented without a side preference. Each paper was also scanned for indications of a shift of main swing directions, similar to what was previously observed in our lab (see "Background" and [42]). If a shift was found, the paper was categorized into "shift over time". 


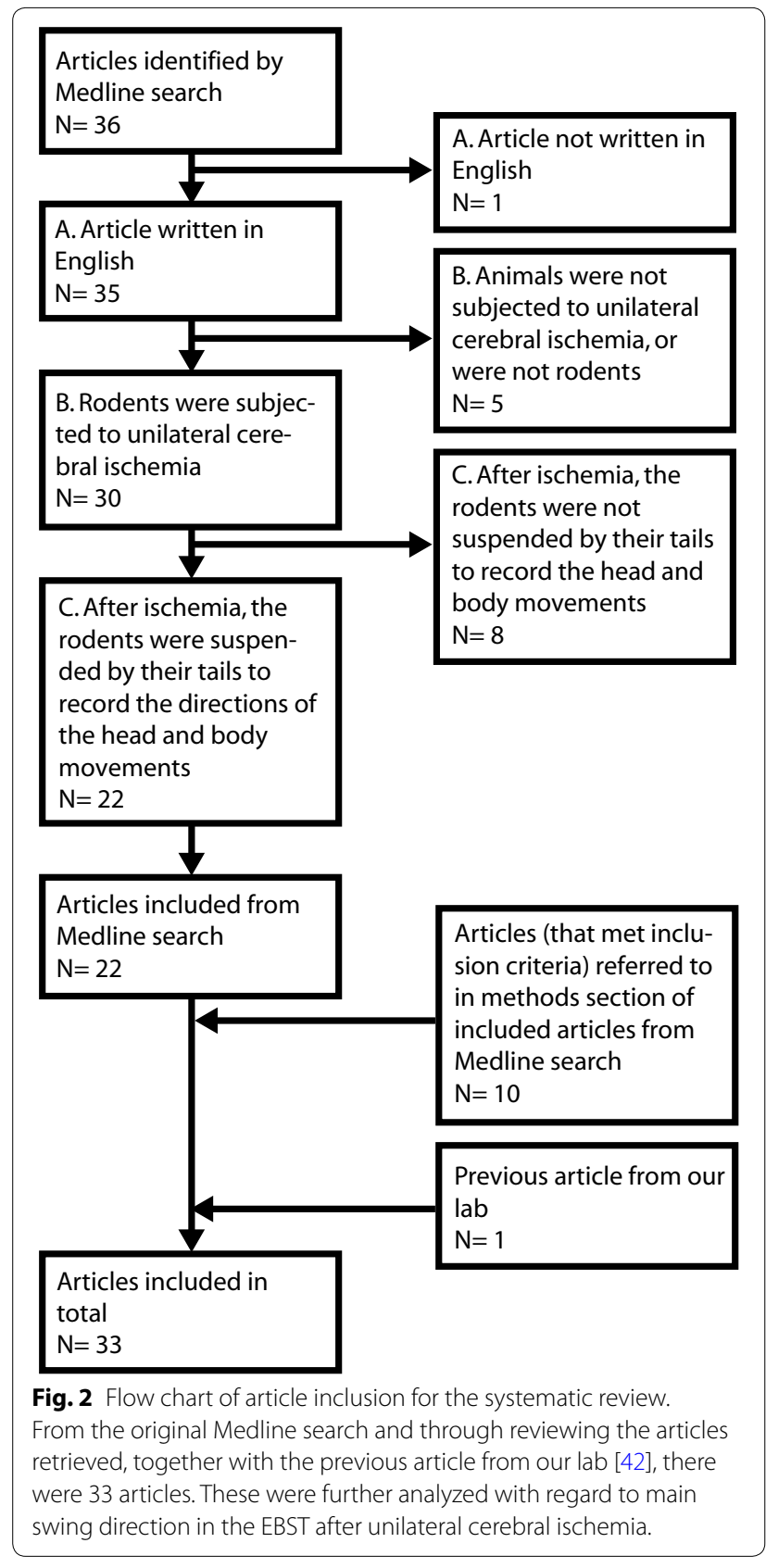

\section{Animals}

Eighty-three adult (age 14 weeks at start of experiment) male and female Sprague-Dawley rats (Taconic Europe, Ry, Denmark) were housed two and two preoperatively (base: $21.5 \times 36 \mathrm{~cm}$, height: $18.5 \mathrm{~cm}$ ) with nesting material (Sizzlenest, Datesand Ltd, Manchester, England) and solitarily postoperatively. The room temperature was $21^{\circ} \mathrm{C}$, a 12 -h light/dark cycle was maintained and the rats had free access to standard rodent chow (801730, Special Diets Service, Essex, England) and water. All procedures were conducted in accordance with the National Committee for Animal Research in Sweden and Principles of Laboratory Animal Care (NIH publication no. 86-23, revised 1985). The study was approved by the Local Ethics Committee for Animal Care and Use at Linköping University.

\section{Grouping}

The rats were randomly allocated into six groups: Four MCAo groups (Male $30 \mathrm{~min}, \mathrm{n}=13$; Male $60 \mathrm{~min}$, $\mathrm{n}=20$; Male $90 \mathrm{~min}, \mathrm{n}=18$; Female $60 \mathrm{~min}, \mathrm{n}=13$ ) and two sham groups (Male sham ICA, $n=9$; Male sham CCA + ECA, $n=10)$. See Fig. 3 for an overview of the experiment. Animals of both sexes, as well as different occlusion times were included to enable a broader investigation of EBST behavior.

\section{Surgical procedures}

For ovariectomy, MCAo and sham surgery, the animals were anesthetized with isoflurane (Forene ${ }^{\circledR}$, Abbott Scandinavia AB, Solna, Sweden), 4.5\% for induction and 1.5\% for maintenance, delivered in a $30 / 70$ mixture of $\mathrm{O}_{2} / \mathrm{N}_{2} \mathrm{O}$. Body temperature was maintained at $37^{\circ} \mathrm{C}$ using a homeothermic blanket connected to a rectal probe (50-7061, Harvard Apparatus, Holliston, MA, USA). Ophtalmic ointment (Lubrithal, VetXX, Uldum, Denmark) was provided for eye protection. For pain relief, $5 \mathrm{mg} / \mathrm{kg}$ bodyweight of carpofen (462986, Rimadyl Vet, Pfizer ApS, Ballerup, Denmark) was administered during ovariectomy (only the females were thus subjected to this treatment, but a washout period of 14 days followed before MCAo). Before MCAo and sham surgery, $1.25 \mathrm{mg} /$ $\mathrm{kg}$ bodyweight of bupivacaine (Marcain, AstraZeneca, Södertälje, Sweden) was administered. Fluid replenishment with $5 \mathrm{~mL}$ saline was given in connection with the MCAo and sham surgery. The skin was cleaned with Iodine solution (Jodopax vet ${ }^{\circledR}$; Pharmaxim AB, Helsingborg, Sweden) before incisions.

14 days prior to MCAo, the female rats (group Female $60 \mathrm{~min}$ ) were ovariectomized via the dorsal route [43].

The groups Male $30 \mathrm{~min}$, Male $60 \mathrm{~min}$, Male $90 \mathrm{~min}$ and Female 60 min were subjected to transient cerebral

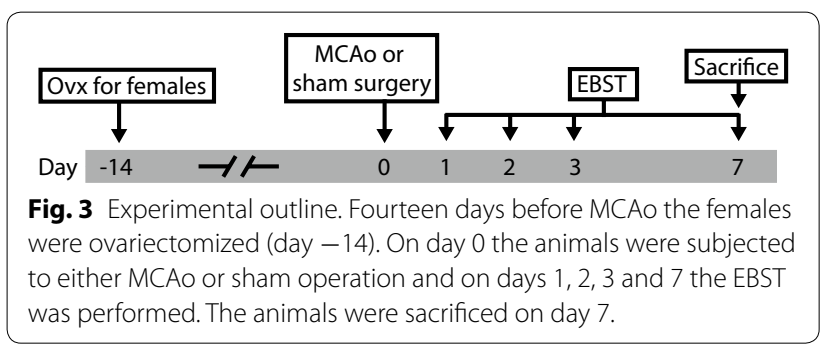


ischemia in the left hemisphere induced by the filament method, based on the procedure originally described by Koizumi [44] and Longa [45]. With the rat in supine position, a $2 \mathrm{~cm}$ cervical midline incision was made and the common (CCA), internal (ICA) and external (ECA) carotid arteries were freed from surrounding tissue. CCA and ECA were ligated with a suture (6-0 silk suture, Johnson \& Johnson, New Brunswick, NJ, USA), while ICA was temporarily clipped with a vascular microclip $(8 \mathrm{~mm}$ artery clip, Rebstock Instruments Gmbh, Dürbheim, Germany). Thereafter, an incision was made in the CCA and a $30 \mathrm{~mm}$ silicone coated 4-0 nylon suture (403756, Doccol, Redlands, CA, USA) was inserted and advanced up ICA approximately $18-20 \mathrm{~mm}$ until a mild resistance was felt, indicating correct placement. The filament was secured by a knot and the animal was allowed to wake up from anesthesia. After 30 (Male $30 \mathrm{~min}$ ), 60 (Male $60 \mathrm{~min}$ and Female $60 \mathrm{~min}$ ) or 90 (Male $90 \mathrm{~min}$ ) minutes of occlusion, during which time the rat was kept in a heated cage $\left(25^{\circ} \mathrm{C}\right)$, it was re-anesthetized to enable filament withdrawal, permanent occlusion of ICA and proper closure of the incision. The rats were allowed to recover in heated cages $\left(25^{\circ} \mathrm{C}\right)$ for $1 \mathrm{~h}$, and during the first $24 \mathrm{~h}$ postoperatively, they were provided water-soaked food pellets in a petri dish on the cage floor to encourage eating. The rats in the sham groups (Male sham ICA and Male sham CCA + ECA) were subjected to the same procedure, with some exceptions. For group Male sham CCA + ECA both CCA and ECA vessels were ligated but no incision was made in CCA and hence no filament was inserted. For group Male sham ICA, only ICA was ligated, no incision was made and no filament was inserted.

\section{Elevated body swing test}

Although EBST is the most common term used to describe the test discussed herein, it has also been called "the tail suspension test" [46]. However, this denomination usually refers to a similar test used for screening antidepressants in mice, in which the degree of immobility is observed rather than the direction of the swings. Yet other names, "C-shaped lateral bending of body" [32] and "hang-tail test" [47], have been used for similar tests.

Before MCAo and on days 1, 2, 3 and 7 (Fig. 3) the EBST was performed for all animals based on the original description by Borlongan et al. [5] with some minor modifications. The rat was put in a transparent cage $(36 \times 19.5 \times 18.5 \mathrm{~cm})$ and allowed to attain a neutral position, with all four paws on the ground. By the base of the tail, it was then elevated to approximately $10 \mathrm{~cm}$ from the bottom of the cage and the direction of the first body swing, i.e. $\mathrm{a}>10^{\circ}$ bending of the upper body out of the vertical axis to either side, was recorded. Before the next swing, the animal was placed back in the cage to reposition. Once it was visibly balanced and not displaying a preference for one side, it was re-suspended. The procedure was repeated 20 times. If the animal did not commence swing behavior, the base of the tail was gently pressed in order to induce this. The examiner alternated the hand used to pick up the rat and the position relative to the testing cage to avoid influencing the direction of swings, and the test was carried without any disturbing objects in the immediate surroundings. The proportion of right-side swings were calculated. For baseline values and testing on day 1 the EBST was performed only once per animal, while days 2, 3 and 7 had two testing sessions where the animals were allowed to rest for approximately $30 \mathrm{~min}$ in between.

To be able to statistically test the shifting behavior, the following definition was used:

1. Pre-MCAo (baseline), the proportion of right-side swings must not be significantly different from 0.5 .

2. On day 1, the proportion of right-side swings should be significantly higher than baseline.

3. On day 2, 3 and 7 the side preference should shift and hence the proportion of right-side swings should be significantly lower than baseline and remain there.

\section{Infarct measurement}

Under anesthesia (see "Surgical procedures" above) the rat was decapitated using a rodent guillotine. The brain was dissected out, cooled in ice water for $5 \mathrm{~min}$ and subsequently sliced in $2 \mathrm{~mm}$ slices using a rat brain matrix (RBM-4000, ASI Instrument Inc., USA). The slices were then soaked for $15 \mathrm{~min}$ in 2\% 2,3,5-triphenyltetrazolium hydrochloride solution (TTC; Sigma-Aldrich Sweden AB, CAS\# 298-96-4, Stockholm, Sweden) at $37^{\circ} \mathrm{C}$ and scanned (Scanjet 2c, Hewlett-Packard, Palo Alto, CA, USA). Infarcts were measured in a similar way as described by Goldlust et al. (8784144), with an automatic $40 \%$ green spectrum threshold (SigmaScan Pro 5, Systat Software Inc, San Jose, CA, USA). Total infarct volume was calculated indirectly according to Swanson et al. [48]:

Corrected infarct volume $=$ [contralateral hemisphere - [ipsilateral hemisphere - crude infarct]]/contralateral hemisphere.

The indirect method (calculation based on remaining viable tissue in the lesioned hemisphere) was chosen to minimize error introduced by loss of brain tissue due to the infarction 7 days after MCAo. Direct measurement of infarct size (pixels) was used to calculate proportion of infarct in cortex and striatum, respectively.

\section{Statistics}

Based on the definition of the shift (see above), occurrence of shifting behavior in all groups subjected to 
MCAo was statistically tested by repeated measures ANOVA with post hoc testing against baseline, Bonferroni corrected. The same method was used for analysis after regrouping of males according to infarct size. For group Male small infarcts Greenhouse-Geisser correction was used due to violation of sphericity (tested with Mauchly's sphericity test). One-sample t tests were used to test if the proportion of right-side swings in the groups at baseline (before MCAo) differed from 0.5.

Comparisons of EBST results (proportion of right-side swings) between the groups Male $60 \mathrm{~min}$ and Female $60 \mathrm{~min}$, and between the male groups (Male $30 \mathrm{~min}$, Male $60 \mathrm{~min}$ and Male $90 \mathrm{~min}$ ) were made by two-way mixed ANOVA with day as within-subjects variable and group as between-subjects variable. Because of unequal variances (Levene's test) in both analyses, data were square root transformed. After square root transformation, Levene's test was performed again and did not show unequal variances.

One-way independent ANOVA was used to compare infarct volumes in the MCAo groups (Female $60 \mathrm{~min}$, Male $30 \mathrm{~min}$, Male $60 \mathrm{~min}$ and Male $90 \mathrm{~min}$ ). Data was square root transformed because of unequal variances (Levene's test). After transformation, Levene's test was performed again and showed no unequal variances. For comparison of the proportion of infarcts in cortex between the MCAo groups (Female $60 \mathrm{~min}$, Male $30 \mathrm{~min}$, Male $60 \mathrm{~min}$ and Male $90 \mathrm{~min}$ ), the non-parametric equivalent to one-way independent ANOVA KruskalWallis test was used since variances were unequal (Levene's test) both before and after square root transformation. Homogeneity of variance for the Kruskal-Wallis test was confirmed by one-way independent ANOVA for the absolute difference between ranks and mean ranks of the groups.

To compare the shifting animals with the non-shifting regarding infarct volume and location of infarct (proportion of infarct in cortex), two two-way ANCOVA models were performed. To control for sex and occlusion time, these variables were included as a fixed categorical factor and a continuous covariate, respectively.

Data are presented as mean \pm SEM throughout the article.

\section{Protocol violations}

The overall mortality of the study was $29 \%$ (24/83, Table 1). All animals that died spontaneously prior to sacrifice on day 7 were excluded from the analyses.

Animals that did not have any visible infarcts with direct measurement (for calculation of proportion of infarct in cortex and striatum, respectively) but still had a positive value for total infarct volume which was calculated with another approach (indirectly according to
Table 1 Mortality in experiment

\begin{tabular}{lc}
\hline Group & Mortality day $\mathbf{- 1 4}$ to $\mathbf{7}$ \\
\hline Male $30 \mathrm{~min}$ & $3 / 13(23 \%)$ \\
Male $60 \mathrm{~min}$ & $10 / 20(50 \%)$ \\
Male $90 \mathrm{~min}$ & $8 / 18(44 \%)$ \\
Female $60 \mathrm{~min}$ & $3 / 13(23 \%)$ \\
Male sham ICA & $0 / 9(0 \%)$ \\
Male sham CCA + ECA & $0 / 10(0 \%)$ \\
Total & $24 / 83(29 \%)$ \\
\hline
\end{tabular}

Swanson [48], described above) were excluded in the analyses of cortex/striatum ratio and differences in proportion of infarcts in cortex. With indirect infarct measurement it is possible to obtain negative values and, as mentioned above, this method was used for calculation of total infarct volume. In 13 animals with very small infarcts, negative values were set to 0 in the analysis.

Actual group sizes after exclusion of animals that died was $\mathrm{n}=10$ for all the MCAo groups, and $\mathrm{n}=9$ and $\mathrm{n}=10$ for the Male sham ICA and Male sham CCA + ECA groups, respectively. For analyses of cortex/ striatum ratio and differences in proportion of infarcts in cortex, however, group sizes were Female $60 \min (\mathrm{n}=9)$, Male $30 \mathrm{~min}(\mathrm{n}=10)$, Male $60 \mathrm{~min}(\mathrm{n}=10)$, Male $90 \min (\mathrm{n}=9)$, Male sham ICA $(\mathrm{n}=8)$ and Male sham $\mathrm{CCA}+\mathrm{ECA}(\mathrm{n}=5)$ since some animals were excluded as described in the preceding paragraph.

\section{Results}

\section{Systematic review}

Although swing activity to the side contralateral to the ischemic hemisphere dominated, a few articles reported ipsilateral swings (14/33 and 3/33 respectively, Table 2). Almost half of the studies (14/33, Table 2) were labeled unclear, i.e. a biased swing activity was described but not whether it was ipsilateral or contralateral. The use of females exclusively was reported in only two of the included papers, hence no comparisons regarding sex differences could be performed. One study, except from our previous, reported a shift in direction over time (Table 2). All studies had at least one group with biased swing activity.

\section{Elevated body swing test}

Of all the groups, only Sham ICA had baseline values for proportion of right-side swings that differed significantly from $0.5[\mathrm{t}(8)=-2,69 ; \mathrm{p}=0.028]$.

When occurrence of shifting behavior was tested according to the definition (see "Methods"), a main effect of time on proportion of right-side swings was 
Table 2 Number of previous articles reporting different directions of biased swing activity [reference in square brackets]

\begin{tabular}{|c|c|c|c|}
\hline Ipsilateral & Contralateral & Unclear & Shift over time \\
\hline \multicolumn{4}{|l|}{ Male } \\
\hline $2[8,21]$ & $9[9,11,15,16,18,20,22,30,34]$ & $13[10,12-14,17,19,23,25-27,29,31,35]$ & $1[36]$ \\
\hline \multicolumn{4}{|l|}{ Female } \\
\hline 0 & $1[24]$ & 0 & $1[42]$ \\
\hline \multicolumn{4}{|c|}{ Unspecified sex or mixed sexes } \\
\hline $1[7]$ & $4[33,37-39]$ & $1[28]$ & 0 \\
\hline \multicolumn{4}{|l|}{ Total } \\
\hline $3[7,8,21]$ & $14[9,11,15,16,18,20,22,24,30,33,34,37-39]$ & $14[10,12-14,17,19,23,25-29,31,35]$ & $2[36,42]$ \\
\hline
\end{tabular}

found in the groups Female $60 \min [F(4,28)=8.63$; $\mathrm{p}<0.0005]$, Male $30 \min [\mathrm{F}(4,36)=4.01 ; \mathrm{p}=0.009]$ and Male $90 \min [\mathrm{F}(4,32)=5.74 ; \mathrm{p}=0.001]$, but not in groups Male $60 \mathrm{~min}[\mathrm{~F}(4,36)=1.69 ; \mathrm{p}>0.05]$, sham ICA $[\mathrm{F}(4,32)=0.22 ; \mathrm{p}>0.05]$ and sham CCA + ECA $[F(4,32)=0.93 ; p>0.05]$. Post-hoc testing against baseline revealed for group Female 60 significantly lower values on days $2(\mathrm{p}=0.008), 3(\mathrm{p}=0.04)$ and $7(\mathrm{p}=0.04)$ (Fig. 4a). Group Male $30 \mathrm{~min}$ had increased proportion of right-side swings compared to baseline on day 1 $(\mathrm{p}=0.004)$, and group Male $90 \mathrm{~min}$ on day $1(\mathrm{p}=0.02)$ and day 7 ( $\mathrm{p}=0.008$ ) (Fig. 4c).

Because of high variability in infarct sizes, an additional analysis of the male rats were done after regrouping according to infarct size (Male small infarcts, Male medium infarcts and Male large infarcts; $\mathrm{n}=10$; Fig. 5). These groups were, similar to what was described for the original groups above, tested regarding proportion of right-side swings according the definition of shifting behavior. A main effect of time was found for groups Male small infarcts $[\mathrm{F}(2,16)=3,70 ; \mathrm{p}=0.048]$ and Male large infarcts $[\mathrm{F}(4,36)=4,92 ; \mathrm{p}=0.003]$ but not for group Male medium infarcts $[F(4,36)=0.73$; $\mathrm{p}>0.05]$. Post-hoc testing against baseline showed significantly higher proportion of right-side swings on day 1 for groups Male small infarcts $(\mathrm{p}=0.008)$ and Male large infarcts $(\mathrm{p}=0.004)$.

The female 60 min group differed significantly from the Male 60 min group regarding proportion of right-side swings over time $[\mathrm{F}(1,18)=6.17 ; \mathrm{p}=0.023]$ while no significances were found when the three male groups were compared in the same way $[\mathrm{F}(2,27)=1.62 ; \mathrm{p}>0.05]$.

Even though no significant shifting behavior was seen on a group level, a separate graph was constructed to illustrate that the phenomenon existed among several individuals. From MCAo groups (Male $30 \mathrm{~min}$, Male $60 \mathrm{~min}$, Male $90 \mathrm{~min}$ and Female $60 \mathrm{~min}$ ), individual rats with proportion of right-side swings $>0.8$ on day 1 and $<0.4$ on days 2 or 3 were plotted (Fig. 6). With this approach, $12 / 40$ rats $(30 \%)$ of the rats met the criteria (3 from Male $30 \mathrm{~min}, 5$ from male $60 \mathrm{~min}$, one from Male $90 \mathrm{~min}$ and 3 from Female $60 \mathrm{~min}$ ). As comparison, when the criteria were inverted (proportion of right-side swings $<0.2$ on day 1 and $>0.6$ on days 2 or 3 ), only one rat was included.

\section{Infarct volume}

No significant differences in infarct volume $[\mathrm{F}(3$, $36)=1.46 ; \mathrm{p}>0.05$ ] or location of infarct (proportion of infarct in cortex; Kruskal-Wallis test; $\mathrm{p}>0.541$ ) were seen between the groups that underwent MCAo.

In the analysis of the shifting animals in Fig. 6 versus the non-shifting animals, no significant effect of shift was seen on infarct volume $[\mathrm{F}(1,35)=0.01 ; \mathrm{p}>0.05]$ or location of infarct [proportion of infarct in cortex; $\mathrm{F}(1$, $31)=0.92 ; \mathrm{p}>0.05]$.

\section{Discussion}

The systematic review revealed that different articles reported diametrically different swing directions in the EBST after unilateral cerebral ischemia, emphasizing the confusion that exists regarding this test. When the shifting behavior, suggested in the preceding study from our lab [42], was statistically tested according the definition presented in "Methods", no significant change in direction was seen in any of the groups. However, the side preference profile of the group designed based on the previous study [42] (Female $60 \mathrm{~min}$ ) still is interesting; a persistent ipsilateral side preference developed but not until day 2. Since rats subjected to MCAo usually are most affected early after stroke, the biggest impact on behavior would have been expected on day 1. Figure 6, with EBST data from shifting animals plotted (data selected post-experiment in such a manner must obviously be interpreted with great caution), shows that although not strong enough to have any major influence on the group curves, a clear shift in swing direction existed among almost a third of the rats. However, this 

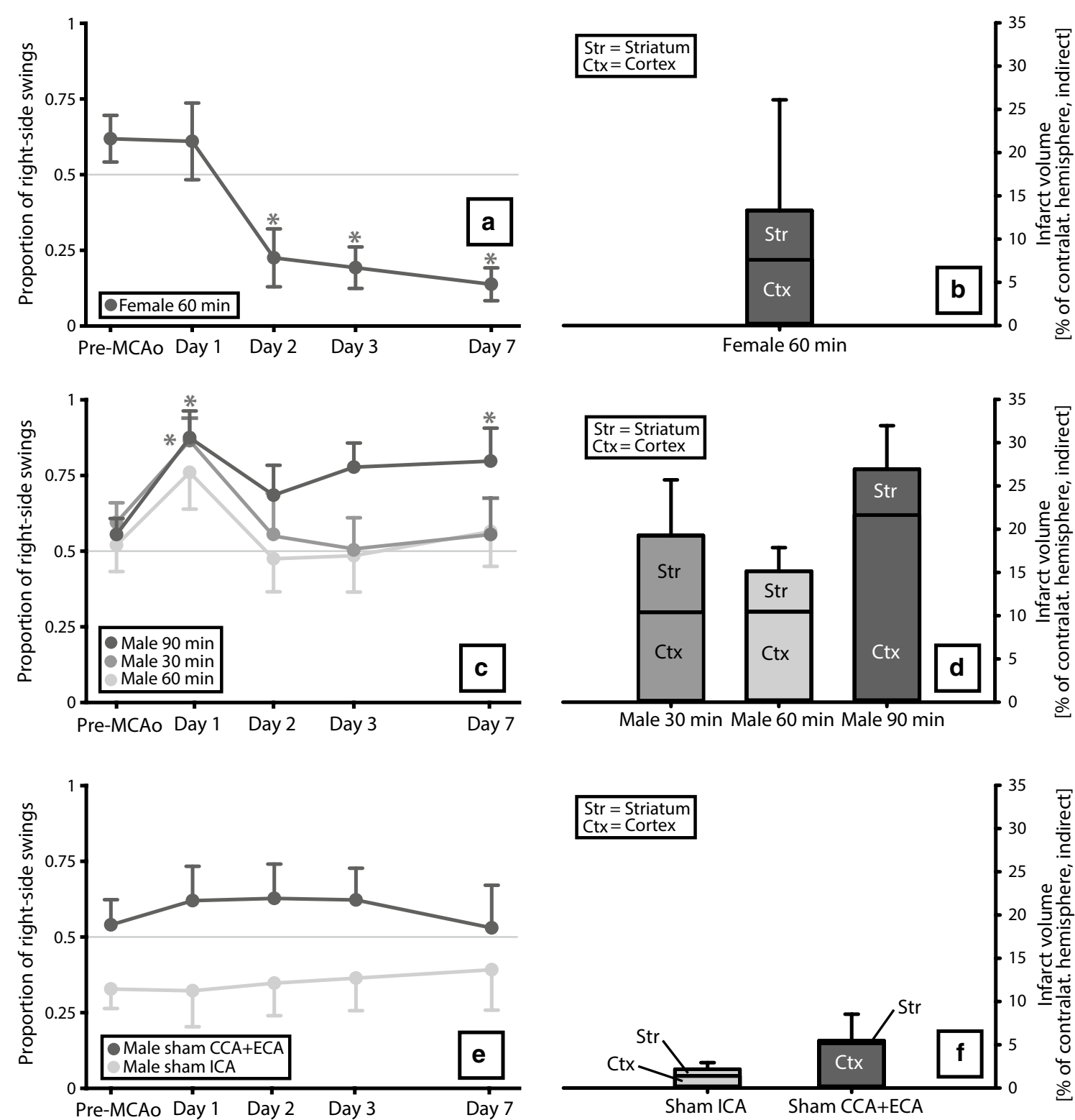

Fig. 4 EBST performance $(\mathbf{a}, \mathbf{c}, \mathbf{e})$ and infarct volumes including location of infarcts $(\mathbf{b}, \mathbf{d}, \mathbf{f})$. There was a significant difference between the EBST curve for group Female $60 \mathrm{~min}$ (a) and Male $60 \mathrm{~min}$ (c) but not for the three male groups (Male $30 \mathrm{~min}$, Male 60 min and Male 90 min). None of the MCAo groups (Male $30 \mathrm{~min}$, Male $60 \mathrm{~min}$, Male $90 \mathrm{~min}$ and Female $60 \mathrm{~min}$ ) differed significantly in infarct volume of location of infarct (proportion of infarct in cortex). Asterisks indicate significant difference in proportion of right-side swings compared to baseline values of the group ( $p<0.05$ ). Mean \pm SEM

shift was not persistent; on day 7 the proportion of rightside swings varies greatly among the rats. One article in the systematic review also reported a change in direction. After right-sided cerebral ischemia in gerbils, the animals displayed right-biased swings (ipsilateral) on the day of ischemia that switched to left-biased swings (contralateral) at 2 days post-ischemia [36]. Thus, the shift had a similar temporal pattern to the one we described but strangely enough it went in the opposite direction, from ipsilateral to contralateral rather than the other way around. Another study from the systematic review did mention the fact that direction of swings when performing the EBST can differ, and location of ischemia was here proposed as the explanatory factor; striatal damage would result in ipsilateral swings whereas cortical or combined damage would make the animals swing 


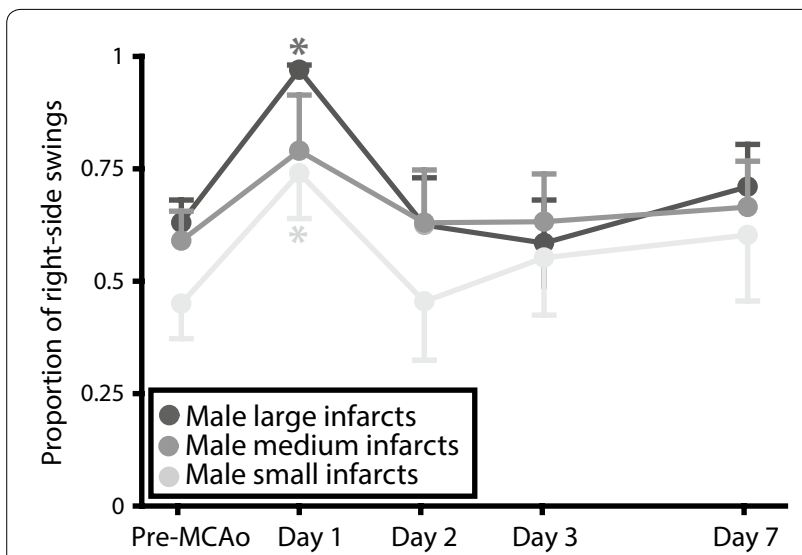

Fig. 5 EBST performance in males regrouped according to infarct size. Because of high variability in infarct sizes, the males were regrouped according to infarct size (Male small infarcts, Male medium infarcts and Male large infarcts) in an additional analysis to reflect actual severity of lesions produced rather than occlusion times. Asterisks indicate significant difference in proportion of right-side swings compared to baseline values of the group $(p<0.05)$.

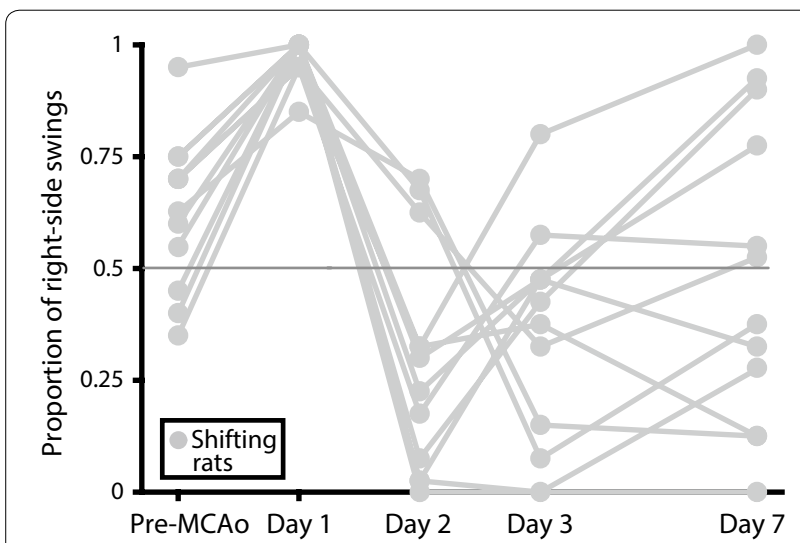

Fig. 6 EBST performance of rats displaying a shift. EBST performance of rats from MCAo groups (Male $30 \mathrm{~min}$, Male $60 \mathrm{~min}$, Male $90 \mathrm{~min}$ and Female $60 \mathrm{~min}$ ) displaying a shift in direction (proportion of right-side swings $>0.8$ on day 1 and $<0.4$ on days 2 or 3 ).

contralaterally [14]. Based on this, the group Female $60 \mathrm{~min}$ (that displayed partial ipsilateral swing tendency) in the current study would have been expected to have a smaller proportion of infarct in cortex. However, we did not find any significant differences between the groups regarding infarct location (proportion of infarct in cortex) or infarct volume. Nor were there any significant differences in the explorative comparison of animals with a shift (Fig. 6) versus non-shifting animals for these two outcomes, further challenging location of infarct as the crucial factor determining swing direction. Because of large variability in infarct sizes in the present study, the male MCAo rats were regrouped according to lesion volume in an additional analysis (Fig. 5). It could be argued that such an approach is more relevant than occlusion time since this reflects the actual sizes of the lesions produced rather than the intentions. No shifting behavior according to the definition was found in these groups either, and no obvious pattern regarding infarct size and swing direction was found. Both the group with the smallest infarcts (Male small infarcts) and the group with the largest infarcts (Male large infarcts) had significantly higher proportion of right-side swings compared to baseline on day 1 , while the rats with middle-sized infarcts (Male medium infarcts) had no significant differences compared to baseline on any of the post-MCAo days. TTC staining 1 week after the MCAo was used in the current study. Although this has been done before $[49,50]$, concerns have been raised regarding the use this method at such a late point in time [51].

ECA supplies tissues around the face of the rat and ligation can cause ischemia in this region [52]. Since two different sham groups were used in the current study, one in which we ligated CCA and ECA during the ischemia induction procedure and one with only ICA ligated, we were able to investigate whether the facial ischemia, by affecting EBST behavior, could have anything to do with the observed shift. For example it could have been that rats with facial ischemia were more prone to swing in the opposite direction (contralateral) early after stroke and that this effect decreased over time resulting in a change in preferred swing direction (neutral or ipsilateral). However, although the curves of the two sham groups in Fig. 4e are somewhat different, the proportion of rightside swings did not change distinctly before versus after surgery in either group and therefore the swing phenomenon seen in the MCAo rats is unlikely to be explained by a mechanism related to ECA ligation and facial ischemia.

In the clinic, a process somewhat similar to a shift can sometimes occur after a stroke. Initially, patients typically suffer from flaccid paralysis which in some patients can develop into spasticity after a few weeks [53]. However, this mechanism is an unlikely explanation for several reasons. First, our shift occurs over days rather than weeks. Secondly, spasticity primarily affects limbs [53], while the current phenomenon seems related to axial muscles. And finally, a transition from flaccid paralysis to spasticity should in theory produce a change from ipsilateral to contralateral swings, i.e. the opposite to what we observed, since ischemia affects the part of the body contralateral to the infarcted hemisphere.

To summarize the discussion regarding possible mechanisms behind a shift, three suggestions were presented: location of infarct, ischemia in the ECA territory and spasticity. No support was found in this study for the former two, and the latter seems theoretically unlikely. 
The most striking result of the experimental part is that the EBST curve for the female rats is noticeably different from the male groups, even when sex is the only differentiating factor (groups Female 60 min versus Male 60 min; Fig. 4). Also, when compared against group baseline values for proportion of right-side swings, the female group (Female $60 \mathrm{~min}$ ) presented with significantly lower values on all timepoints except the first, while the two of the male groups, Male $30 \mathrm{~min}$ and Male $90 \mathrm{~min}$, on the contrary had values significantly higher than baseline on one and two timepoints, respectively. The fact that we earlier obtained similar results with females [42], corroborates the notion of an effect of sex on EBST performance. The fact that the females are ovariectomized makes estrogens less likely as an explanation for this. Differences in other hormones such as testosterone, or in brain wiring between female and male rats could perhaps contribute, but these suggestions are merely speculations. Unfortunately, only two studies [24, 42] from the systematic review reported the use of females exclusively and therefore it is hard to draw any conclusions from this. However, it is worth mentioning that one of these two studies, the one not performed our lab, had contralateral swings [24], contradicting the abovementioned idea of a sex effect.

\section{Strengths and weaknesses}

A drawback of this study is the mortality, which was higher than what we have seen previously in our lab. Perhaps this was a consequence of intense EBST testing; even though the procedure is not long in duration it is probably stressful for the animal to repeatedly be suspended upside-down. To try to reduce the stress imposed on the rats early after stroke, only one testing session was performed on day 1, whereas the rats were tested twice on days 2, 3 and 7. Cerebral blood flow measurement to ensure successful filament insertion and occlusion was not used which might have decreased the success rate of the ischemia inductions.

A strength is that we included several groups that differed in terms of sex and occlusion time. This made it possible to show how the EBST performance can change with altered conditions. The inclusion of a thorough systematic review of the existing literature on the subject also adds weight to the study.

\section{Conclusions}

The present study shows, both experimentally and through systematic literature review, that the direction of biased swing activity in the EBST for rodents after cerebral ischemia can differ and even shift over time in some situations. Although it does not provide an explanation to why this is the case, it highlights the importance of clear and adequate reporting of behavioral tests for lateralization. Since we could not find a swing profile consistent among all groups, not even if only the first day post-MCAo (day 1) was considered, we cannot recommend the use of this test for motor asymmetry after MCAo in rats.

\section{Abbreviations}

EBST: elevated body swing test; MCAo: middle cerebral artery occlusion; CCA: common carotid artery; ICA: internal carotid artery; ECA: external carotid artery; TTC: 2,3,5-triphenyltetrazolium hydrochloride.

\section{Authors' contributions}

El contributed to the design, performed part of the data collection, did the analyses and drafted the manuscript. JG contributed to the design, performed part of the data collection and revised the manuscript. ET and AT contributed to the design and revised the manuscript. JOS contributed to the design, performed part of the data collection and revised the manuscript. All authors read and approved the final manuscript.

\section{Author details}

${ }^{1}$ Division of Microbiology and Molecular Medicine, Department of Clinical and Experimental Medicine, Department of Clinical Chemistry, Faculty of Health Sciences, Center for Diagnostics, Linköping University, Region Östergötland, Linköping, Sweden. ${ }^{2}$ Division of Neuroscience, Department of Clinical and Experimental Medicine, Faculty of Health Sciences, Department of Neurosurgery, Anaesthetics, Operations and Specialty Surgery Center, Linköping University, Region Östergötland, Linköping, Sweden. ${ }^{3}$ Vårdvetenskapligt Forskningscentrum/Centre for Health Sciences, Örebro University Hospital, County Council of Örebro, Örebro, Sweden. ${ }^{4}$ School of Health and Medical Sciences, Örebro University, Örebro, Sweden.

\section{Acknowledgements}

We gratefully acknowledge the technical assistance of Hua Dock (PhD) and the anonymous reviewers for their valuable comments and suggestions. The study was supported by Region Östergötland/Linköping University, Sweden.

\section{Compliance with ethical guidelines}

\section{Competing interests}

The authors declare that they have no competing interests.

Received: 6 February 2015 Accepted: 28 July 2015

Published online: 05 August 2015

\section{References}

1. Mukherjee D, Patil CG (2011) Epidemiology and the global burden of stroke. World Neurosurg 76(6 Suppl):S85-S90

2. Dirnagl U, Endres M (2014) Found in translation: preclinical stroke research predicts human pathophysiology, clinical phenotypes, and therapeutic outcomes. Stroke 45(5):1510-1518

3. DeVries AC, Nelson RJ, Traystman RJ, Hurn PD (2001) Cognitive and behavioral assessment in experimental stroke research: will it prove useful? Neurosci Biobehav Rev 25(4):325-342

4. Hoyman L, Weese GD, Frommer GP (1979) Tactile discrimination performance deficits following neglect-producing unilateral lateral hypothalamic lesions in the rat. Physiol Behav 22(1):139-147

5. Borlongan CV, Sanberg PR (1995) Elevated body swing test: a new behavioral parameter for rats with 6-hydroxydopamine-induced hemiparkinsonism. J Neurosci Off J Soc Neurosci 15(7 Pt 2):5372-5378

6. Borlongan CV, Randall TS, Cahill DW, Sanberg PR (1995) Asymmetrical motor behavior in rats with unilateral striatal excitotoxic lesions as revealed by the elevated body swing test. Brain Res 676(1):231-234

7. Borlongan CV, Cahill DW, Sanberg PR (1995) Locomotor and passive avoidance deficits following occlusion of the middle cerebral artery. Physiol Behav 58(5):909-917 
8. Borlongan CV, Tajima Y, Trojanowski JQ, Lee VM, Sanberg PR (1998) Transplantation of cryopreserved human embryonal carcinoma-derived neurons (NT2N cells) promotes functional recovery in ischemic rats. Exp Neurol 149(2):310-321

9. Shyu WC, Lin SZ, Yang HI, Tzeng YS, Pang CY, Yen PS et al (2004) Functional recovery of stroke rats induced by granulocyte colony-stimulating factor-stimulated stem cells. Circulation 110(13):1847-1854

10. Borlongan CV, Skinner SJ, Geaney M, Vasconcellos AV, Elliott RB, Emerich DF (2004) Intracerebral transplantation of porcine choroid plexus provides structural and functional neuroprotection in a rodent model of stroke. Stroke 35(9):2206-2210

11. Borlongan CV, Tajima Y, Trojanowski JQ, Lee VM, Sanberg PR (1998) Cerebral ischemia and CNS transplantation: differential effects of grafted fetal rat striatal cells and human neurons derived from a clonal cell line. Neuroreport 9(16):3703-3709

12. Willing AE, Lixian J, Milliken M, Poulos S, Zigova T, Song S et al (2003) Intravenous versus intrastriatal cord blood administration in a rodent model of stroke. J Neurosci Res 73(3):296-307

13. Borlongan CV (2000) Motor activity-mediated partial recovery in ischemic rats. Neuroreport 11(18):4063-4067

14. Johnston RE, Dillon-Carter O, Freed WJ, Borlongan CV (2001) Trophic factor secreting kidney cell lines: in vitro characterization and functional effects following transplantation in ischemic rats. Brain Res 900(2):268-276

15. Chiang YH, Lin SZ, Borlongan CV, Hoffer BJ, Morales M, Wang Y (1999) Transplantation of fetal kidney tissue reduces cerebral infarction induced by middle cerebral artery ligation. J Cereb Blood Flow Metab 19(12):1329-1335

16. Pin-Barre C, Laurin J, Felix MS, Pertici V, Kober F, Marqueste T et al (2014) Acute neuromuscular adaptation at the spinal level following middle cerebral artery occlusion-reperfusion in the rat. PLoS One 9(2):e89953

17. Katnik C, Garcia A, Behensky AA, Yasny IE, Shuster AM, Seredenin SB et al (2014) Treatment with afobazole at delayed time points following ischemic stroke improves long-term functional and histological outcomes. Neurobiol Dis 62:354-364

18. Eckmann DM, Armstead SC (2013) Surfactant reduction of cerebral infarct size and behavioral deficit in a rat model of cerebrovascular arterial gas embolism. J Appl Physiol 115(6):868-876

19. Li F, Miao ZN, Xu YY, Zheng SY, Qin MD, Gu YZ et al (2012) Transplantation of human amniotic mesenchymal stem cells in the treatment of focal cerebral ischemia. Mol Med Rep 6(3):625-630

20. Jin K, Mao X, Xie L, Greenberg RB, Peng B, Moore A et al (2010) Delayed transplantation of human neural precursor cells improves outcome from focal cerebral ischemia in aged rats. Aging Cell 9(6):1076-1083

21. Emerich DF, Silva E, Ali O, Mooney D, Bell W, Yu SJ et al (2010) Injectable VEGF hydrogels produce near complete neurological and anatomical protection following cerebral ischemia in rats. Cell Transplant 19(9):1063-1071

22. Shen $\mathrm{H}$, Wang $\mathrm{Y}$ (2010) Correlation of locomotor activity and brain infarction in rats with transient focal ischemia. J Neurosci Methods 186(2):150-154

23. Kozak A, Ergul A, El-Remessy AB, Johnson MH, Machado LS, Elewa $\mathrm{HF}$ et al (2009) Candesartan augments ischemia-induced proangiogenic state and results in sustained improvement after stroke. Stroke 40(5):1870-1876

24. Chen JR, Cheng GY, Sheu CC, Tseng GF, Wang TJ, Huang YS (2008) Transplanted bone marrow stromal cells migrate, differentiate and improve motor function in rats with experimentally induced cerebral stroke. J Anat 213(3):249-258

25. Hurtado O, Cardenas A, Pradillo JM, Morales JR, Ortego F, Sobrino T et al (2007) A chronic treatment with CDP-choline improves functional recovery and increases neuronal plasticity after experimental stroke. Neurobiol Dis 26(1):105-111

26. Borlongan CV, Sumaya IC, Moss DE (2005) Methanesulfonyl fluoride, an acetylcholinesterase inhibitor, attenuates simple learning and memory deficits in ischemic rats. Brain Res 1038(1):50-58

27. Borlongan CV, Hadman M, Sanberg CD, Sanberg PR (2004) Central nervous system entry of peripherally injected umbilical cord blood cells is not required for neuroprotection in stroke. Stroke 35(10):2385-2389
28. Vendrame M, Cassady J, Newcomb J, Butler T, Pennypacker KR, Zigova T et al (2004) Infusion of human umbilical cord blood cells in a rat model of stroke dose-dependently rescues behavioral deficits and reduces infarct volume. Stroke 35(10):2390-2395

29. Yu G, Xu L, Hadman M, Hess DC, Borlongan CV (2004) Intracerebral transplantation of carotid body in rats with transient middle cerebral artery occlusion. Brain Res 1015(1-2):50-56

30. Roof RL, Schielke GP, Ren X, Hall ED (2001) A comparison of long-term functional outcome after 2 middle cerebral artery occlusion models in rats. Stroke 32(11):2648-2657

31. Borlongan CV, Hida H, Nishino H (1998) Early assessment of motor dysfunctions aids in successful occlusion of the middle cerebral artery. Neuroreport 9(16):3615-3621

32. van der Staay FJ, Augstein KH, Horvath E (1996) Sensorimotor impairments in rats with cerebral infarction, induced by unilateral occlusion of the left middle cerebral artery: strain differences and effects of the occlusion site. Brain Res 735(2):271-284

33. Tomac AC, Grinberg A, Huang SP, Nosrat C, Wang Y, Borlongan C et al (2000) Glial cell line-derived neurotrophic factor receptor alpha1 availability regulates glial cell line-derived neurotrophic factor signaling: evidence from mice carrying one or two mutated alleles. Neuroscience 95(4):1011-1023

34. Pollak J, Doyle KP, Mamer L, Shamloo M, Buckwalter MS (2012) Stratification substantially reduces behavioral variability in the hypoxic-ischemic stroke model. Brain Behav 2(5):698-706

35. Jin K, Wang X, Xie L, Mao XO, Greenberg DA (2010) Transgenic ablation of doublecortin-expressing cells suppresses adult neurogenesis and worsens stroke outcome in mice. Proc Natl Acad Sci USA 107(17):7993-7998

36. Katsumata N, Kuroiwa T, Yamada I, Tanaka Y, Ishibashi S, Endo S et al (2006) Neurological dysfunctions versus apparent diffusion coefficient and $\mathrm{T} 2$ abnormality after transient focal cerebral ischemia in Mongolian gerbils. Acta Neurochir Suppl 96:279-282

37. Ishibashi S, Kuroiwa T, Endo S, Okeda R, Mizusawa H (2003) A comparison of long-term neurological symptoms after two different focal ischemic models in Mongolian gerbils. Acta Neurochir Suppl 86:159-162

38. Ishibashi S, Kuroiwa T, Endo S, Okeda R, Mizusawa H (2003) Neurological dysfunctions versus regional infarction volume after focal ischemia in Mongolian gerbils. Stroke 34(6):1501-1506

39. Daadi MM, Lee SH, Arac A, Grueter BA, Bhatnagar R, Maag AL et al (2009) Functional engraftment of the medial ganglionic eminence cells in experimental stroke model. Cell Transplant 18(7):815-826

40. Bederson JB, Pitts LH, Tsuji M, Nishimura MC, Davis RL, Bartkowski H (1986) Rat middle cerebral artery occlusion: evaluation of the model and development of a neurologic examination. Stroke 17(3):472-476

41. Garcia JH, Wagner S, Liu KF, Hu XJ (1995) Neurological deficit and extent of neuronal necrosis attributable to middle cerebral artery occlusion in rats. Statistical validation. Stroke 26(4):627-634 (discussion 635)

42. Strom JO, Ingberg E, Theodorsson E, Theodorsson A (2013) Effects of high and low 17beta-estradiol doses on focal cerebral ischemia: negative results. Sci Rep 3:3111

43. Strom JO, Theodorsson A, Ingberg E, Isaksson IM, Theodorsson E (2012) Ovariectomy and 17 beta-estradiol replacement in rats and mice: a visual demonstration. J Vis Exp JoVE 64:e4013

44. Koizumi J, Yoshida Y, Nakazawa T, Ooneda G (1986) Experimental studies of ischemic brain edema. 1. A new experimental model of cerebral embolism in rats in which recirculation can be introduced in the ischemic area. Jpn J Stroke 8:1-8

45. Longa EZ, Weinstein PR, Carlson S, Cummins R (1989) Reversible middle cerebral artery occlusion without craniectomy in rats. Stroke 20(1):84-91

46. Wang-Fischer $Y$, Koetzner L (2009) Endpoints for stroke studies. In: WangFischer $Y$ (ed) Manual of stroke models in rats. CRC Press, Taylor \& Francis Group, Boca Raton, pp 193-222

47. Barth TM, Schallert T (1987) Somatosensorimotor function of the superior colliculus, somatosensory cortex, and lateral hypothalamus in the rat. Exp Neurol 95(3):661-678

48. Swanson RA, Morton MT, Tsao-Wu G, Savalos RA, Davidson C, Sharp FR (1990) A semiautomated method for measuring brain infarct volume. J Cereb Blood Flow Metab 10(2):290-293 
49. Lin TN, He YY, Wu G, Khan M, Hsu CY (1993) Effect of brain edema on infarct volume in a focal cerebral ischemia model in rats. Stroke 24(1):117-121

50. Huang J, Tao J, Xue X, Yang S, Han P, Lin Z et al (2013) Gua Lou Gui Zhi decoction exerts neuroprotective effects on post-stroke spasticity via the modulation of glutamate levels and AMPA receptor expression. Int J Mol Med 31(4):841-848

51. Liszczak TM, Hedley-Whyte ET, Adams JF, Han DH, Kolluri VS, Vacanti FX et al (1984) Limitations of tetrazolium salts in delineating infarcted brain Acta Neuropathol 65(2):150-157
52. Trueman RC, Harrison DJ, Dwyer DM, Dunnett SB, Hoehn M, Farr TD (2011) A critical re-examination of the intraluminal filament MCAO model: impact of external carotid artery transection. Transl Stroke Res 2(4):651-661

53. Keenan M, Mehta S, McMahon P (2014) Rehabilitation. In: Skinner $H$, McMahon P (eds) Current diagnosis and treatment in orthopedics, 5 edn. McGraw-Hill, New York
Submit your next manuscript to BioMed Central and take full advantage of:

- Convenient online submission

- Thorough peer review

- No space constraints or color figure charges

- Immediate publication on acceptance

- Inclusion in PubMed, CAS, Scopus and Google Scholar

- Research which is freely available for redistribution

Submit your manuscript at www.biomedcentral.com/submit

(O) Biomed Central 